\title{
A política de contratação de professores temporários em Portel (PA)
}

\section{The policy of hiring temporary teachers in Portel (PA) La política de contratación de maestros temporales en Portel (PA)}

ARIEL FELDMAN

Orcid Id: http://orcid.org/0000-0002-8894-8554

Universidade Federal do Pará

CHARLES ALBERTO DE SOUZA ALVES

Orcid Id: https://orcid.org/0000-0002-5095-8802

Instituto Federal de Educação, Ciência e Tecnologia do Pará

\begin{abstract}
Resumo: A pesquisa analisa a relação entre contratação de professores temporários e disputa pelo poder local em Portel (PA). Trata-se de estudo de caso descritivo e exploratório, em abordagem qualitativa, pautado em referencial teórico que privilegia um enfoque a partir do município. Realizou-se pesquisa in loco em janeiro de 2018, além de análise bibliográfica e documental. O resultado da pesquisa demonstra a importância da indicação de professores temporários na disputa pelo poder local, bem como indícios de que relações de natureza clientelísticas são a base dessas contratações.
\end{abstract}

Palavras-chave: Política Educacional; Educação Básica; Poder Local; Contrato Temporário de Professores

Abstract: This paper aims to analyze the relationship between the hiring of temporary teachers and the local power struggle in Portel (PA). This is a descriptive and exploratory case study, in a qualitative approach, based on a theoretical framework that privileges studies of the municipality level. On-site research was conducted in January 2018, in addition to bibliographic and documentary analysis. The result of the research demonstrates the importance of the appointment of temporary teachers in the dispute for local government, as well as indicates that clientelistic relationships are the basis of these bires.

Keywords: Educational Policy; Basic Education; Local Power; Temporary Teacher's Contract.

Resumen: Esta investigación analiza la relación entre la contratación de maestros sin estabilidad laboral y la disputa por el poder local en Portel (PA). Este es un estudio de caso en un enfoque cualitativo, basado en un marco teórico que sostiene un enfoque a partir de la municipalidad. La investigación in loco se realizó en enero de 2018, más allá del análisis bibliográfico y documental. El resultado del estudio demuestra la importancia de nombrar maestros sin estabilidad laboral en la disputa por el poder local, así como también indica que las relaciones clientelares son la base de estas contrataciones.

Palabras clave: Politica Educativa; Educación Básica; Poder Local; Contrato Temporal de Maestros. 


\section{INTRODUÇÃO}

O fenômeno da existência em larga escala de professores temporários nas redes de educação básica e pública no Brasil é estrutural e persistente (MARQUES, 2006; FERREIRA, 2013; BRITO, 2013; NASCIMENTO, 2014; FERREIRA, 2016; QUIBAO NETO e PINTO, 2016; SANTOS 2016; SEKI et. al, 2017). Entre 2013 e 2018, eles representaram entre $28 \%$ e $31 \%$ do total de docentes. Na zona rural, esse fenômeno é mais acentuado, pois nesse mesmo período os professores temporários representaram entre $42 \%$ e $46 \%$ do total (CENSO ESCOLAR). Segundo pesquisa recente (SEKI et. al, 2017, p. 946), “os municípios, em 2015, apresentavam maior percentual de turmas atendidas por trabalhador temporário, 36\% frente a 32\% nas Redes Estaduais".

Este estudo de caso, realizado em Portel, município do interior do Pará, com 53\% da população na zona rural (IBGE, 2010), pretende ser uma contribuição para entender a persistência do grande número de professores temporários nas redes municipais. O objetivo da pesquisa é investigar a relação entre a contratação de professores temporários e a disputa pelo poder local em Portel. A existência desse tipo de contrato no universo docente é multicausal, tendo como fatores explicativos de destaque, os quais estão interrelacionados, a precarização do trabalho preconizada pelo receituário neoliberal (FERREIRA, 2016) e as restrições orçamentárias das redes de ensino (SANTOS, 2016). Assim, pretende-se sugerir mais um fator explicativo para a persistência desse fenômeno, sobretudo em municípios onde o mercado de trabalho formal é extremamente restrito. Nesses municípios, a política de fundos, instituída a partir de 1996, transformou o mercado de trabalho docente na principal fonte de empregos.

A pesquisa in loco foi realizada em janeiro de 2018, contudo, a contextualização retrocede ao início da implantação da política de fundos e do processo de municipalização do Ensino Fundamental (EF) em Portel, iniciado em 1999. Como indicam Gouveia e Souza (2015), a política de fundos representa uma nova fase da história do financiamento da educação básica no Brasil. A Emenda Constitucional (EC) n ${ }^{\circ} 14$ de 1996, que instituiu o Fundo de Manutenção e Desenvolvimento do EF e Valorização do Magistério (Fundef), induziu um amplo processo de municipalização do EF no Brasil, tendo sido o Pará um dos estados pioneiros. Como veremos, o Fundef e, a partir de 2007, o Fundo de Manutenção e Desenvolvimento do Educação Básica e Valorização do Magistério (Fundeb), impactaram o contexto político, econômico e social em Portel de forma significativa. 
Num primeiro momento, iremos descrever a metodologia da pesquisa. Em seguida, teceremos considerações teóricas, de modo a justificar nossa abordagem feita do e a partir do município, bem como definiremos conceitualmente a categoria clientelismo. $\mathrm{Na}$ sequência, elencaremos os marcos legais que regulamentam a existência de professores temporários, no Brasil e em Portel, bem como empreenderemos uma sintética revisão bibliográfica sobre essa modalidade de contratação docente. Depois, iremos contextualizar o município de Portel, mostrando o impacto que a política de fundos teve na economia, no orçamento municipal e no mercado de trabalho. Por fim, será realizada a análise dos dados obtidos por meio de entrevistas, coleta documental (Plano Municipal de Educação, Plano de Carreira e Remuneração do Magistério Público e Lei Orgânica do Município de Portel) e observação participante.

\section{NOTA METODOLÓGICA}

Entre 2010 e 2017, os pesquisadores tiveram contato direto, regular e sistemático com o universo docente de uma série de municípios do interior do Pará, como Cametá, Baião, Igarapé-Miri, Mocajuba, Tomé-Açu, Pacajá, Altamira, Bragança e Abaetetuba. Dessa forma, foi possível observar como a contratação de professores temporários estava diretamente imbricada com a política local. Optou-se, então, por realizar, in loco, durante 10 dias, em janeiro de 2018, um estudo de caso único (YIN, 2001; ALVES-MAZZOTTI, 2006) em Portel, localidade onde os índices de professores temporários estavam acima da média dos demais municípios do Brasil.

Foram realizadas conversas informais com mais de 30 professores temporários, entrevistas com 2 vereadores que tiveram mandatos nas duas últimas legislaturas (doravante vereador 1 e 2) e 2 professores temporários (doravante professor 1 e 2). Padrões de conduta relatados por muitos observadores receberam maior valor probatório em relação aos relatados por apenas um observador (AUYERO e BENZECRY, 2017, p. 183).

A pesquisa foi realizada em abordagem eminentemente qualitativa (BOGDAN e BIKLEN, 1994). Contudo, não acreditando em fronteiras estritamente definidas entre o qualitativo e o quantitativo (CRESWELL, 2010), foram utilizadas diversas bases de dados para a descrição da realidade municipal (FINBRA, IBGE, SIOPE e CENSO ESCOLAR). Os dados foram sempre tratados e organizados sob a perspectiva do munícipio, aspecto que será aprofundado a seguir. 


\section{REFERENCIAL TEÓRICO}

Para pensar o nosso objeto de pesquisa, a política de contratação de professores temporários em Portel, inspirados em Lopez (2004), nos pautamos numa articulação entre duas vertentes das Ciências Sociais no Brasil: a Antropologia da Política e a Sociologia Política de Maria Isaura Pereira de Queiroz.

Na década de 1990, surgiu o Núcleo de Antropologia da Política (NuAP), um esforço coletivo de pesquisa (PALMEIRA e GOLDMAN, 1996). Para nossa pesquisa, uma dimensão oriunda das pesquisas antropológicas, isto é, a forma como os humanos significam suas atitudes, ganha relevância metodológica. Como bem definiu Bezerra (1999, p. 11), um estudo de antropologia da política "não está preocupado com o dever ser da política, mas com o modo como efetivamente ela é praticada", privilegiando, portanto, "a política em ação". Ainda segundo Bezerra (Idem, p. 11), a natureza metodológica desse tipo de investigação privilegia "construção da análise a partir do modo como as pessoas que participam do exercício da política concebem sua experiência".

A abordagem antropológica da política é um dos campos que mais produziu pesquisas em torno do fenômeno do clientelismo (cf. BEZERRA, 1999; PALMEIRA e GOLDMAN, 1996; KUSHNIR, 1999). Na boa síntese de Bezerra, predomina um certo consenso de que as relações assim denominadas se caracterizam especialmente por serem relações do tipo assimétricas, isto é, são estabelecidas entre pessoas (patrão e cliente) que não possuem o mesmo poder (econômico e político), prestígio e status. Além disso, ela se distingue por ser uma relação do tipo pessoal (em que predominam os contatos face a face), pela troca de serviços e bens materiais e imateriais (gentilezas, deferência, lealdade e proteção) entre os parceiros e pelo seu conteúdo moral (que remete frequentemente à honra dos parceiros).

Hilgers (2011), preocupada com o mau uso do conceito clientelismo, muitas vezes confundido com patrimonialismo, corrupção ou compra de votos, sugere quatro características basilares para o clientelismo, o qual deve sempre ser entendido num plano microssociológico: difusão pelo tecido social (diffuseness), longevidade, contato face-a-face e desigualdade.

Destaquemos, agora, as contribuições teórico-metodológicas de Queiroz (1976). Ela elencou um tripé básico no qual a sociologia política brasileira deveria se pautar. Uma dessas três premissas era a de realizar pesquisas empíricas efetuadas a partir do município. Queiroz voltava-se contra uma abordagem que reproduzisse "o mito de que um grupinho de figurões, na Corte e na Capital Federal, comandava as pugnas partidárias, puxando de longe os cordõezinhos que moviam os coronéis no interior". Para ela, "ponto de partida desses estudos 
deve ser o plano em que o fenômeno político é mais violento e colore todos os outros aspectos da vida em grupo - o plano municipal” (QUEIROZ, 1976, p. 25 e 30). A Sociologia Política de Queiroz, assim, nos fornece subsídio para uma proposta teórica que não enquadre os atores municipais como agentes passivos do processo político. Sem desprezar a estrutura federativa brasileira estabelecida pela Constituição Federal (CF) de 1988, que concentra o processo decisório no poder central e delega a execução de políticas públicas aos entes subnacionais (ARRETCHE, 2012), esse estudo entende os atores políticos municipais como agentes ativos na implementação dessas políticas gestadas na esfera nacional e estadual.

\section{PROFESSORES TEMPORÁRIOS: BREVE REVISÃO DE LITERATURA}

Importante ressaltar que a nomenclatura para docentes não concursados pode variar (Cf. SANTOS, 2016), bem como a natureza do contrato. Optamos aqui, por utilizar a nomenclatura que aparece no Censo Escolar e que tem aplicação prática para o caso de Portel.

Se a legislação busca minimizar o número de temporários nas redes de ensino, a literatura caminha na mesma direção, isto é, indica que os efeitos desse tipo de contratação causam, de um modo geral, problemas no processo pedagógico, na gestão e nas condições de trabalho docente. A contratação temporária na administração pública sempre será necessária, para substituir, de forma imediata e ágil, profissionais afastados por problemas de saúde ou aposentados. Contudo, como apontam Quibao Neto e Pinto (2016, p. 2), "o que vem ocorrendo dentro das redes públicas de educação básica está longe de ser reposição."

Ferreira (2016), pesquisando a condição de trabalho do professor temporário da rede municipal de Fortaleza, apontou que esses profissionais demonstram significativos sentimentos de adoecimento e sofrimento. Marques (2006), em estudo de caso em torno dos professores temporários no Colégio Liceu do Conjunto Ceará, também em Fortaleza, mas da rede estadual, informa que esses profissionais recebem salários atrasados e são obrigados a mudar de escola semestralmente. Também investigando a rede estadual do Ceará, mas sob outra perspectiva, Nascimento (2014) constatou que a proficiência em matemática e português dos alunos regidos por professores temporários é mais baixa do que a dos alunos regidos por concursados (sua referência foram alunos do $9^{\circ}$ ano na Prova Brasil de 2011). 
Nauroski (2014), analisando a condição dos professores temporários da rede estadual do Paraná, identificou indícios de uma subjetividade negativa peculiar nestes profissionais, diretamente relacionada às condições precárias de trabalho às quais eles são submetidos. Ferreira (2013), também estudando os professores temporários da rede estadual do Paraná, constatou que eles não são protegidos pela legislação trabalhista e não têm os direitos estabelecidos pelo Plano de Carreira e Remuneração do Magistério Público garantidos, vivendo sob constante incerteza e trabalhando em condições precárias.

Por fim, cabe ressaltar que nessa breve revisão de literatura há indícios de que estudos sobre redes estaduais são mais frequentes (BRITO, 2013), destacandose a paulista (QUIBAO NETO E PINTO, 2016; SANTOS, 2016), a paranaense (FERNANDES, 2014; NAUROSKI, 2014) e a cearense (MARQUES, 2006; NASCIMENTO, 2014), bem como pesquisas realizadas em capitais de estados (FERREIRA, 2016). Esse artigo pretende contribuir com uma outra perspectiva de análise, que é entender a importância da indicação de professores temporários na disputa política pelo poder local em um município interiorano de médio porte, no qual o mercado de trabalho assalariado é extremamente precário.

\section{PROFESSORES TEMPORÁRIOS: PRINCIPAIS MARCOS LEGAIS}

O artigo 37 da CF, em redação dada pela EC no 19 de 1998, que estabelece os princípios da administração pública direta e indireta, entre eles o da impessoalidade, preconiza, no inciso II, que "a investidura em cargo ou emprego público depende de aprovação prévia em concurso público de provas ou de provas e títulos (...) ressalvadas as nomeações para cargo em comissão(...).” No inciso IX, afirma que "a lei estabelecerá os casos de contratação por tempo determinado para atender a necessidade temporária de excepcional interesse público". Por sua vez, o artigo 206, inciso V, em redação dada pela EC no 53 de 2006, estabelece a valorização dos profissionais da educação escolar da rede pública através do "ingresso exclusivamente por concurso público de provas e títulos".

Tendo em vista que a CF remete a elaboração de lei infraconstitucional, tendo em vista, ainda, que em 2011, o Supremo Tribunal Federal reiterou a importância de lei municipal para regular a contratação temporária para atender a interesse público excepcional (BRASIL, 2011), vejamos o que estabelece a Lei Orgânica do Município de Portel. Se a CF indica duas exceções à investidura em cargo público por concurso (cargo comissionado e excepcional interesse público), a lei municipal só faz menção a cargos comissionados, sendo o inciso II do art. 87 
da lei orgânica (PORTEL, 1990) uma cópia literal do inciso IX do art. 37 da CF. Em síntese, a principal lei municipal silencia sobre a contração temporária para atender casos excepcionais de interesse público.

O Plano Nacional de Educação, de 2014, com metas decenais, em sua meta 18, estabelece um prazo de 2 anos para que todos os sistemas de ensino tenham planos de carreira, tendo como base o piso nacional salarial profissional. A estratégia 18.1 prevê

\begin{abstract}
estruturar as redes públicas de educação básica de modo que, até o início do terceiro ano de vigência deste PNE, 90\% (noventa por cento), no mínimo, dos respectivos profissionais do magistério (...) sejam ocupantes de cargos de provimento efetivo e estejam em exercício nas redes escolares a que se encontrem vinculados (BRASIL, 2014).
\end{abstract}

O Plano Estadual de Educação (PEE) reproduz as metas e estratégias do PNE acima mencionadas. Destaca-se, em relação ao PEE, que na análise situacional relativa à meta 18 , não são mostrados dados relativos aos tipos de contratos existentes nas redes de ensino (PARÁ, 2015, p. 28-29).

O Plano Municipal de Educação (PME) de Portel destaca, na análise situacional da meta 18 do PNE, que, quando foi elaborado o Plano de Carreira e Remuneração do Magistério Público (PCCR) do município, em 2001, 90\% dos professores trabalhavam com contratos temporários (PORTEL, 2015, p. 320). Tal informação, como veremos, não pôde ser cotejada com o Censo Escolar, que diferencia o tipo de contrato dos docentes a partir de 2011. O PME relata que ocorreram concursos públicos em 2005, 2006, 2007 e 2012. Assim, conforme o PME, mesmo com essa sequência de concursos melhorando a situação, o munícipio, ainda contava, em 2015, com 38\% do total de professores da rede como temporários (Idem, p. 321). Veremos, na tabela 2, que esses dados diferem do levantamento que fizemos no Censo Escolar, que indica, para 2015, 48\% de temporários. Por fim, a estratégia 18.2 do PME prevê que "realizar concursos públicos específicos na área educacional de modo que, até o terceiro ano de vigência deste PME, 85\% (oitenta e cinco por cento), no mínimo, dos respectivos profissionais do magistério (...) sejam ocupantes de cargos de provimento efetivo e estejam em exercício nas redes escolares a que se encontrem vinculados." Em 2017, terceiro ano de vigência do PME, apenas 49\% dos professores de Portel eram efetivos (CENSO ESCOLAR).

Por fim, vejamos o que estipula o PCCR de Portel. Destaque-se, que desde 2009 existiram diversas tentativas para reformular o PCCR de 2001 (cf. PORTEL, 2015, p.323), tendo a prefeitura criado, através de um decreto, uma comissão para reformulação do mesmo em 2017 (PORTEL, 2017). Contudo, o PCCR de 2001 
ainda é o vigente. Destaque-se, ainda, que os professores temporários, via de regra, não são, na prática, contemplados pelo PCCR, em Portel e nas demais redes municipais e estaduais (cf. FERREIRA, 2013).

O artigo 21 do PCCR estabelece que "o provimento inicial dos cargos efetivos dependerá de pré-aprovação em Concurso Público de provas e títulos obedecida a ordem de classificação", e no parágrafo $3^{\circ}$ acrescenta que "fica o Poder Executivo obrigado a realizar concursos de ingresso sempre que o número de cargos vagos atingirem a 30\% (trinta por cento) do conjunto de cargos do Magistério Público" (PORTEL, 2001). Contudo, no seu artigo 47 estabelece o dispositivo que, por não ter sido atualizado desde 2001, se constitui em mecanismo legal que de alguma forma respalda o alto número de docentes não concursados no município. Esse artigo, estabelece o "número de cargos da Carreira do Magistério Público Municipal”, com 420 professores da Educação Básica I, 50 professores da Educação Básica II. São 470 vagas para professores concursados, segundo o PCCR de 2001, número que, na prática, se manteve até 2017, como veremos na tabela 2.

Vejamos, agora, como a política de fundos e a municipalização do EF em Portel transformou a Secretaria Municipal de Educação (SEMED) na principal empregadora do município.

\section{PORTEL, A POLÍTICA DE FUNDOS E O MERCADO DE TRABALHO}

Portel situa-se na mesorregião do Marajó, a 270 quilômetros de Belém, num trajeto fluvial de aproximadamente 12 horas. Tinha 38.297 habitantes em 2000, 52.172 em 2010, e estima-se que 62.043 em 2019, com 33.694 eleitores. Em 2010, 52\% da população vivia na zona rural. Tem mais de $52.172 \mathrm{~km}^{2}$, uma extensão territorial maior que a do estado do Sergipe, o que faz de Portel um dos municípios com menor densidade demográfica do Brasil. Em 2010, seu IDHM era de 0,483 (muito baixo), o que o coloca na posição $5553^{\circ}$ entre os 5570 municípios do país. O Ideb da rede pública de Portel, em 2017, para os anos iniciais do EF, foi de 3,2, sendo assim o $5454^{\circ}$ do Brasil e o $137^{\circ}$ dos 144 municípios do Pará. Para os anos finais, o Ideb foi de 3,2, ficando em $4969^{\circ}$ entre os municípios do país e o $96^{\circ}$ do Pará (IBGE; TSE; PNUD).

O gráfico 1 sintetiza a trajetória econômica do munícipio nas últimas duas décadas. 


\section{Gráfico 1 - Participação em percentual por setor no Valor Adicionado Bruto (VAB) a preços correntes total, Portel (2002-2016) ${ }^{1}$}

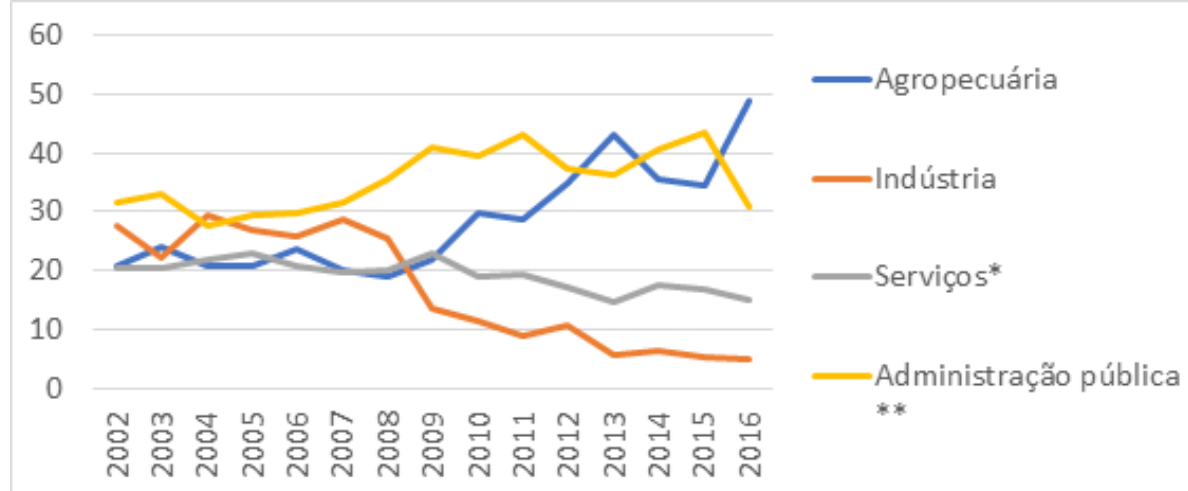

Fonte: IBGE (elaboração própria). * Exclusive administração, defesa, educação e saúde públicas e seguridade social. ** Administração, defesa, educação e saúde públicas e seguridade social

Percebe-se que, depois da crise econômica mundial de 2009, há uma queda significativa na participação da indústria no VAB de Portel, tendo em vista que a indústria madeireira da região entra em declínio. Essa predatória atividade industrial, que flutua segundo as oscilações do mercado externo, ainda tem importância na região, mas bem menor que outrora. A economia de Portel tem como atividade econômica basilar o agroextrativismo familiar, com destaque para a farinha de mandioca, sendo que a fronteira sul do município já sofre as consequências da expansão do agronegócio e do desmatamento. Destaca-se, também, e isso interessa diretamente ao nosso estudo, o peso da administração pública na economia de Portel, sempre maior que $27 \%$, chegando a representar, em 2015, 43\% do VAB municipal.

Vejamos, agora, na tabela 1, o impacto da política de fundos - Fundef e Fundeb - no orçamento municipal. Não interessa para essa pesquisa o crescimento real do orçamento, que pode ser definido como ouro de tolo, porque se aumentaram os recursos, aumentaram as reponsabilidades, isto é, os gastos. Nas palavras de Gemaque (2004), o Fundef, no Pará, gerou um "fetiche", pois os gestores municipais visualizavam, sobretudo, o aumento dos recursos, sem pensar no lado do crescimento das despesas. Contudo, o número de matrículas da rede municipal também cresceu exponencialmente. Antes da municipalização, em 1997, a rede tinha 3.902 alunos. Com a transferência de alunos da rede estadual para a municipal e com uma corrida por matrículas no EF induzida pelo Fundef, esse número subiu para 13.255, em 1999 e 15.876, em 2003, estabilizando-se em 
um patamar aproximado de 20.000 alunos a partir de 2008. O valor per capita do Fundef/Fundeb, em Portel, só ultrapassou o mínimo nacional estabelecido anualmente por portarias ministeriais, interministeriais e decretos em 2011. A educação em Portel era e ainda é subfinanciada. ${ }^{2}$

Dessa forma, o que precisa ser observado na tabela 1, é o peso relativo do Fundef/Fundeb no âmbito municipal.

\section{Tabela 1 - Receita municipal de Portel em comparação com receitas tributárias e Fundef/Fundeb, em preços correntes (1994-2018) ${ }^{3}$}

\begin{tabular}{|c|c|c|c|c|c|c|}
\hline & Ano & Receitas Correntes (A) & Receitas Tributárias (B) & $\mathrm{B} / \mathrm{A}(\%)$ & Fundef/Fundeb* $(C)$ & $\mathrm{C} / \mathrm{A}(\%)$ \\
\hline & 1994 & $1.315 .914,40$ & $6.739,90$ & $1 \%$ & & \\
\hline & 1995 & $2.912 .964,56$ & $23.676,66$ & $1 \%$ & & \\
\hline & 1996 & $3.667 .271,89$ & $23.782,54$ & $1 \%$ & & \\
\hline & 1997 & $4.155 .776,04$ & $30.947,25$ & $1 \%$ & & \\
\hline \multirow{4}{*}{ Fundef } & 2000 & $9.800 .424,84$ & $125.636,36$ & $1 \%$ & $3.618 .976,80$ & $37 \%$ \\
\hline & 2001 & $11.597 .937,64$ & $87.378,25$ & $1 \%$ & $2.794 .945,61$ & $24 \%$ \\
\hline & 2002 & $16.213 .699,74$ & $433.793,45$ & $3 \%$ & $5.070 .206,54$ & $31 \%$ \\
\hline & 2006 & $30.124 .665,21$ & $1.070 .104,09$ & $4 \%$ & $9.851 .885,21$ & $33 \%$ \\
\hline \multirow{11}{*}{ Fundeb } & 2007 & $41.088 .142,64$ & $1.332 .131,16$ & $3 \%$ & $15.475 .818,54$ & $38 \%$ \\
\hline & 2008 & $50.194 .625,99$ & $1.372 .545,84$ & $3 \%$ & $20.594 .383,40$ & $41 \%$ \\
\hline & 2009 & $53.773 .295,00$ & $405.439,00$ & $1 \%$ & $24.504 .412,00$ & $46 \%$ \\
\hline & 2010 & $65.903 .514,00$ & $3.293 .775,00$ & $5 \%$ & $28.761 .631,00$ & $44 \%$ \\
\hline & 2011 & $85.361 .889,27$ & $2.753 .024,20$ & $3 \%$ & $40.750 .076,45$ & $48 \%$ \\
\hline & 2012 & $95.418 .766,56$ & $3.773 .923,73$ & $4 \%$ & $46.540 .161,67$ & $49 \%$ \\
\hline & 2013 & $97.325 .628,40$ & $4.423 .813,92$ & $5 \%$ & $46.287 .044,90$ & $48 \%$ \\
\hline & 2014 & $109.906 .664,14$ & $3.559 .231,41$ & $3 \%$ & $54.267 .950,18$ & $49 \%$ \\
\hline & 2015 & $120.759 .593,11$ & $3.621 .883,00$ & $3 \%$ & $62.640 .791,12$ & $52 \%$ \\
\hline & 2017 & $127.014 .422,61$ & $6.658 .951,23$ & $5 \%$ & $69.212 .444,18$ & $54 \%$ \\
\hline & 2018 & $136.463 .221,60$ & $3.550 .601,10$ & $3 \%$ & $72.691 .508,44$ & $53 \%$ \\
\hline
\end{tabular}

Fonte: FINBRA (elaboração própria) *Já incluída a complementação da União.

Destaquemos dois aspectos da tabela 1. Primeiro, se entre 2002 e 2006, o Fundef já representava entre 33\% e 37\% do orçamento municipal, a partir de 2007 a participação do Fundeb nas receitas correntes de Portel aumentou até representar a 53\%, em 2018. Portel é um município superavitário na política de fundos, historicamente colocando mais recursos do que recebendo. Em 2017,

2 Uma consulta rápida no Simcaq (Simulador de custo-aluno qualidade) demonstra o subfinanciamento da educação básica em Portel. Disponível em https://simcaq.c3sl.ufpr.br/ [acesso em 12/nov/2019]

3 Foram excluídos da tabela os anos em que Portel não consta no FINBRA. 
teve um resultado líquido nas transferências do Fundeb de $\mathrm{R} \$ 31.521 .414,03$ (SIOPE). Outro aspecto importante é que o Pará. desde o início da política de fundos, recebe complementação da União, pouco expressiva durante o período do Fundef, mas durante o Fundeb apresentou impacto considerável do ponto de vista municipal. Destaquemos, em segundo lugar, a pouca participação das receitas tributárias (impostos, taxas e contribuições de melhoria) no orçamento de Portel. Como boa parte dos municípios pequenos ou médios no Brasil, a maior parte das receitas é oriunda de transferências intergovernamentais.

O mínimo de $60 \%$ do Fundef/Fundeb deve ser gasto em remuneração do magistério. Em 2016 esse percentual, em Portel, foi de 78,43\%. Decorre, então, que com a política de fundos a Secretaria Municipal de Educação (SEMED) se tornou a maior empregadora do município, como pode ser observado na tabela 2.

\section{Tabela 2 - Pessoal ocupado assalariado e os professores da rede municipal de Portel (2011-2017)}

\begin{tabular}{|c|c|c|c|c|c|c|c|}
\hline Ano & $\begin{array}{c}\text { Assalariados } \\
\text { (A) }\end{array}$ & $\begin{array}{c}\text { Prof. } \\
\text { Concursados } \\
\text { (B) }\end{array}$ & $\begin{array}{c}\text { Prof. } \\
\text { temporários } \\
\text { (C) }\end{array}$ & $\begin{array}{c}\text { Total de prof. } \\
\text { (D) }\end{array}$ & $\mathbf{C / D}(\%)$ & $\mathbf{C / A}(\%)$ & D/A (\%) \\
\hline 2011 & 2252 & 415 & 357 & 772 & $46 \%$ & $16 \%$ & $34 \%$ \\
\hline 2012 & 2072 & 365 & 444 & 809 & $55 \%$ & $21 \%$ & $39 \%$ \\
\hline 2013 & 1266 & 463 & 419 & 882 & $48 \%$ & $33 \%$ & $70 \%$ \\
\hline 2014 & 2611 & 459 & 383 & 842 & $45 \%$ & $15 \%$ & $32 \%$ \\
\hline 2015 & 3559 & 455 & 425 & 880 & $48 \%$ & $12 \%$ & $25 \%$ \\
\hline 2016 & 2507 & 477 & 452 & 929 & $49 \%$ & $18 \%$ & $37 \%$ \\
\hline 2017 & 4002 & 485 & 501 & 986 & $51 \%$ & $13 \%$ & $25 \%$ \\
\hline
\end{tabular}

Fonte: IBGE - Cadastro Central de Empresas e Censo Escolar (elaboração própria)

Em primeiro lugar, como já foi observado, é preciso destacar que o percentual de professores temporários da rede municipal de Portel nunca esteve próximo às metas estipuladas pelo PNE, PEE e PME. Em 2017, segundo ou terceiro ano de vigência desses planos, o percentual de temporários permaneceu no mesmo patamar observado na série histórica iniciada em 2011, ano em que o Censo Escolar começa a registrar essa modalidade de contrato docente. Em segundo lugar, é preciso notar que apesar de discreta, existe uma prevalência de professores temporários na zona rural. De 2013 a 2017, entre 51\% e 68\% dos professores temporários de Portel trabalhavam na zona rural (CENSO

4 Recorte cronológico iniciado em 2011, primeiro ano em que o Censo Escolar registra modalidades de contratação docente, e finalizado em 2017, último ano em o IBGE registra o número de assalariados. 
ESCOLAR). Segundo entrevista do vereador 2, que será analisada adiante, "aqui a maioria dos [professores] contratados trabalham no campo, quando chega em época de campanha, eles têm que ir pra rua trabalhar pro candidato dele".

Em terceiro lugar, destaque-se a importância do magistério no mercado de trabalho em Portel. Entre 2011 e 2017, conforme mostra a última coluna da tabela 2, o total de professores da rede municipal sempre representou mais que $25 \%$ dos assalariados em Portel. Os professores temporários, por sua vez, representaram entre $12 \%$ e $33 \%$ dos assalariados do município. A importância política da indicação de professores temporários decorre, em parte, do baixo número de empregos assalariados em Portel. ${ }^{5}$

\section{REDES DE CLIENTELA E CONTRATAÇÃO DE PROFESSORES TEMPORÁRIOS}

Segundo o professor 1, "todo ano tem uma correria de contratação, todo mundo tem que ir pra viação [sic] correr atrás do seu vereador, quem você apoiou. Tipo, se você ficou neutro, então não apoiou ninguém, não trabalhou com ninguém, então tá [sic] fora da educação". Esse mesmo professor, que trabalhou por 6 anos na condição de temporário, relata que perdeu o emprego na troca de governo, em 2017, pois estava "do lado de um vereador que tinha muita força política porque ele era irmão do prefeito" e que, mesmo reeleito, perdeu força, foi para oposição, porque o prefeito não se reelegeu.

Situação semelhante foi relatada pelo professor 2:

foi o meu irmão que conseguiu o emprego pra mim. Justamente porque nessa época ele tinha ligações fortes de política, porque ele era diretor, e sempre os diretores são indicados por políticos do município, porque são cargos de confiança e, nessa época o meu irmão tinha um vínculo muito grande com vereadores e com prefeito também (PROFESSOR 2).

Quando muda o governo, em 2017, o irmão do professor 2 é retirado da direção e ele perde o emprego. Contudo, um antigo colega de trabalho foi indicado para ser o novo diretor da escola.

5 Tendo em vista as limitações dessa pesquisa, não foi possível explicar a oscilação no quantitativo de assalariados observada na tabela 2 
Ele [o novo diretor] foi lá comigo, conversou e falou olha eu quero te colocar lá porque tu trabalha bem, conheço teu trabalho, é um excelente profissional. Só que existe algumas coisas por trás disso, e justamente era o vereador que tinha colocado ele lá. E aí ele me chamou pra uma conversa com esse vereador, e nesse dia foi eu e mais dois amigos meus. Lá tivemos uma conversa meio que informal, mas é lógico que por trás disso existe uma troca de favores, no caso, permitindo que eu fique lá trabalhando porque esse vereador tem uma influência muito forte com o secretário de educação porque eles estão no poder, eles são também do lado do prefeito. Então foi como uma troca de favores, você fica no trabalho, mas lá na frente eu vou precisar da tua ajuda, quando vier a pré-candidatura e vou tentar me reeleger. Então existe sim aqui no município uma relação muito forte de contratados e o poder político do município, muitas vezes existe uma influência muito grande deles dentro do sistema educacional do município (PROFESSOR 2).

A literatura sobre clientelismo destaca que uma das características desse tipo de relação é o contato face-a-face e a reciprocidade entre pessoas com poderes desiguais (HILGERS, 2011; AUYERO e BENZECRY, 2017; BEZERRA, 1999). Nossa pesquisa indicou que a contratação de professores temporários perpassa, quase que invariavelmente, por vários momentos em que o cliente (professor) estabelece contato face-a-face com o patrão ou com intermediários. A literatura demonstra, também, a importância que os intermediários têm nas relações clientelísticas, sendo que sua denominação pode variar: broker, no mundo anglosaxônico, puntero, na periferia de Buenos Aires (AUYERO e BENZECRY, 2017), ou cabo eleitoral na sociologia política de Queiroz (1976). Nossa pesquisa indica que a figura do diretor exerce essa função de broker ou cabo eleitoral. O relato do vereador 1 sugere uma rede hierárquica de relações clientelísticas, na qual a capacidade de mobilização eleitoral determina o lugar que cada um ocupa:

O processo político em campanha é dado de acordo com o número de cabos eleitorais que arrumam dez votos. No caso cada professor é considerado um cabo eleitoral que garante no mínimo 10 votos. E conforme o desempenho desses professores nas comunidades ou nos bairros, locais que eles atuam eles vão tendo cargo maior. Por exemplo um professor que [...] garante 10 votos em determinado local [...] ele tem uma carga horária ampliada de 100 horas mês para 200 horas e se ele tiver um desempenho maior em votos no local que ele garantiu, ele pode se tornar um coordenador indicado por dentro da secretaria de educação pelo vereador[...]. Ou até mesmo cargo de direção de escola. Então é como se fosse uma troca de votos, uma troca de favores políticos, ajuda o professor e o professor ajuda na política, mais ou menos dessa forma que se dá a relação no processo eleitoral. (VEREADOR 1).

Vejamos, agora, o relato do vereador 2 sobre como ocorre a contratação de professores temporários. 
Como que isso tem funcionado no município de Portel? Que é uma preocupação que também a gente tem... isso tem sido peça de troca, na maioria das vezes o político oferece a vaga de emprego, a carga horária pro trabalhador em troca de apoio. E por conta disso a maioria dos políticos não gosta de realizar concursos. Quando realiza concursos você perde a moeda de troca, porque se você realiza concurso, o pessoal paga, vai pra lá, estuda e passa no curso, deixa de ter aquela dívida com a pessoa. Esse é o pensamento, que o considero arcaico porque eu acho que nós temos que trabalhar resultados. [...] Já imaginou o professor que trabalha com uma turma de 25 alunos, constantemente tem 20 pais pra conversar. Aí tu multiplica, entre pais e mães são 40, aí se tu for trabalhar mesmo essa relação família-escola, tu vai multiplicar isso por três e vai 60 e depois eles vão ser multiplicador [sic.]. Essa é a estratégia que a maioria dos políticos tem usado. Pega o professor, nomeia. O professor vira amigo do comunitário, depois vira amigo do pai do aluno, começa a discutir aquilo que é interessante pra ele. $\mathrm{O}$ professor além de ser professor, ele é cabo eleitoral, ele pega o político e leva pra base. Às vezes o político não tem nenhum voto naquela base lá , mas o professor vai construindo essa base, e aí constrói, leva o político pra lá e dali começa uma construção de dependência [grifo dos autores], e isso tem praticamente definido o processo de eleição no município de Portel (VEREADOR 2).

O vereador 2, em sua entrevista, usou 4 vezes a palavra "dependência". Segundo ele, "o candidato a prefeito faz a reunião com determinados grupos de professores, esse professor traz outros grupos formados aqui, tipo célula. Uma liderança tem outras lideranças, que tem outras lideranças. E aí fica essa cadeia, essa teia de coisas que vai gerar toda essa dependência.”. As pesquisas que indicam que o clientelismo é um mecanismo de manutenção da estrutura social destacam que essas relações são longevas, isto é, não se trata de apenas um contato face-aface, mas de reiterados contatos ao longo do tempo (AUYERO e BENZECRY, 2017; GRAHAM, 1999).

\section{AS CONDIÇÕES DO TRABALHO DOCENTE TEMPORÁRIO}

As entrevistas e a observação participante revelaram percepções consensuais de que o contrato docente temporário é prejudicial do ponto de vista pedagógico. Segundo o professor 1 "aqui a política não te deixa trabalhar direito, não te deixa legal”. Segundo o professor 2, entre 2010 e 2012 ele assinou um memorando para receber entre fevereiro e novembro. Se a situação já era precária, recebendo apenas 10 meses por ano, depois de 2013 esse memorando deixou de ser assinado, sendo que os professores deixaram de receber o mês de julho. 
E como assinávamos [até 2012] esse memorando com esses dez meses, significava que no mês de julho nós teríamos que receber. No mês de julho que era as férias recebíamos. Agora, como a gente assina no final do semestre, por exemplo de fevereiro a junho, quando a gente assina em junho a gente é destratado. (PROFESSOR 2).

A observação participante e conversas informais com outros professores temporários indicam que atrasos nos salários são corriqueiros, bem como essa prática de pagar apenas 9,10 ou 11 meses de salário durante o ano letivo.

\section{A RELAÇÃO ENTRE PODER EXECUTIVO E LEGISLATIVO}

Pesquisa realizada no arquivo da Câmara Municipal de Portel revela que, logo após a posse do novo governo, entre fevereiro e março de 2017, uma série de ofícios foram escritos por vereadores para a SEMED, indicando a nomeação de professores temporários e outros profissionais da educação. A pesquisa demonstrou que um prefeito, em Portel, para contar com a maioria do legislativo, depende da capacidade de liberar indicações de cargos na SEMED, a maior empregadora do município. Vejamos o relato do vereador 1 :

É importante dizer que até mesmo no processo de eleição da presidência da Câmara Municipal acontece esse tipo de envolvimento dos professores. Alguns professores [...] são tidos como cabos eleitorais mais acirrados mais fiéis dos vereadores. Eles acabam fazendo esse processo de articulação, tipo assim, o prefeito quer fazer o presidente da Câmara que seja um vereador do lado dele, né? Pra ele vencer a oposição ele acaba chamando os vereadores que foram eleitos por outras coligações, e fazendo acordos nesse sentido [...]. Como eu já vi numa gestão anterior o prefeito ofereceu uma escola de médio porte, uma escola que tem um cargo de direção duas vice-direções e mais ou menos [...] 24 turmas. Então essas 24 turmas vão ter uma gama de professores lotados pra trabalhar nessa escola. E toda essa carga horária junto com o cargo de direção e coordenação vem de porteira fechada, como eles dizem, o vereador que passar pro lado do prefeito pra votar no candidato do prefeito na presidência da câmara, esse Vereador ele automaticamente já ganha uma escola de Porteira fechada para indicar diretor vice-diretor e os professores (VEREADOR 1)

As entrevistas indicam que algumas regiões do município se constituem em nichos políticos de vereadores. Segundo o professor 1 "por exemplo, no Ajará tem um político, e aí eles falam que o dono do Ajará é o fulano, prefeito deu pra ele o Ajará, aí ele emprega, ele desemprega, coloca professores". 


\section{ATUAÇÃO DO MINISTÉRIO PÚBLICO}

Como indicou Brito (2013), o Ministério Público (MP) teve atuação decisiva para que diversos concursos públicos para o magistério fossem realizados em diversas redes estaduais. Em Portel, a atuação do MP também foi decisiva. Segundo relato do vereador 2 , alguns dos concursos públicos realizados na primeira década do século XXI só aconteceram por conta de uma ação do MP, informação que essa pesquisa não foi capaz de verificar. O Sindicato dos Trabalhadores em Educação Pública do Estado do Pará (Sintepp) teve atuação decisiva ao provocar o MP em boa parte dessas ações.

Em setembro de 2018, foi firmado um Termo de Ajuste de Conduta (TAC), no qual o município se comprometeu a realizar concurso público e a não contratar mais servidores temporários (MPPA, 2019). O concurso público foi realizado no início de 2019 e o resultado homologado em março. Segundo o edital retificado (PORTEL, 2018, p. 5), foram disponibilizadas 94 vagas imediatas para professor e 94 vagas de cadastro reserva, totalizando 188 vagas. Mesmo que todos os classificados em cadastro reserva fossem convocados, o que parece não ter sido a vontade prefeitura, pois apenas 106 docentes foram convocados em maio, ainda teríamos um quantitativo necessário de 348 professores temporários, levando em consideração que eles eram 536 em 2018.

O TAC, porém, foi descumprido, indicando resistência por parte das instituições municipais. O MP, então, ajuizou Ação Civil Pública em 19 de agosto de 2019, exigindo "suspensão de contratações de servidores temporários, exoneração dos que ingressaram após a homologação do concurso público realizado pelo Município em 2018 e nomeação dos concursados". Segundo o promotor, "nota-se que o gestor mantém elevado número de servidores em designação temporária preterindo de forma arbitrária os candidatos aprovados no concurso público". Em relação à SEMED, o promotor destaca o "que se verifica no caso da educação é uma clara tentativa de manter nos quadros da educação pessoas apadrinhadas e até mesmo nepotismo" (MPPA, 2019).

\section{CONSIDERAÇÕES FINAIS}

O objetivo da pesquisa era investigar a relação entre contratação de professores temporários e disputa pelo poder local em Portel. Constatou-se que a indicação de professores temporários exerce grande relevância nas disputas pelo poder municipal, com indícios de que relações de natureza clientelísticas são a base dessas contratações. 
Tomemos emprestado, assim, a terminologia criada por Cunha (2006) para definir as frequentes mudanças de rumo no Ministério da Educação: administração educacional zigue-zague. Conforme Queiroz (1976, p. 30), no plano municipal, a sociabilidade política é mais violenta e "colore todos os outros aspectos da vida em grupo". É preciso ter uma compreensão mais aprofundada das idiossincrasias municipais, de modo a entender o zigue-zague da gestão educacional no seio do ente federativo que foi responsabilizado pela Educação Infantil e EF no Brasil.

\section{REFERENNCIAS}

ALVES-MAZZOTTT, A. J. Usos e abusos dos estudos de caso. Cadernos de Pesquisa, v.36, n.129, p. 637-651, 2006.

ARRETCHE, M. Democracia, federalismo e centralização no Brasil. Rio de Janeiro, Editora FGV/Fiocruz, 2012.

AUYUERO, J; BENZECRY, C. The Practical Logic of Political Domination: Conceptualizing the Clientelist Habitus. Sociological Theory, v. 35, n. 3, p. 179-199, 2017.

BEZERRA, M. O. Em nome das "bases": política, favor e dependência pessoal. Rio de Janeiro: Relume Dumará, 1999.

BOGDAN, R. C.; BIKLEN, S. K. Investigação qualitativa em educação: uma introdução à teoria e aos métodos. Portugal: Porto Editora, 1994.

BRASIL. Supremo Tribunal Federal. Habeas Corpus n. 104.078 Paciente: Itamar Francisco Machado Borges. Relator: Min. Gilmar Mendes. Brasília, 07 de junho de 2011.

BRITO, V. L. A. O plano nacional de educação e o ingresso dos profissionais do magistério da educação básica. Educação \& Sociedade, v. 34, n. 125, p. 1251-1267, out./dez. 2013

CENSO ESCOLAR. Disponível em http://portal.inep.gov.br/censo-escolar> ou $<$ https://dadoseducacionais.c3sl.ufpr.br/\#/. Acesso em 11 de dezembro de 2019. 
CRESWELL, J. W. Projeto de pesquisa: métodos qualitativo, quantitativo e misto. Porto Alegre: Artmed, 2010.

CUNHA, L. A. Zigue-Zague no Ministério da Educação: uma visão da educação superior. Revista Contemporânea de Educação, v. 1, n. 1, 2006.

FERREIRA, D. C. K. Os professores temporários da educação básica da rede pública estadual do Paraná: a flexibilização das contratações e os impactos sobre as condições de trabalho docente. Dissertação (Mestrado em Educação). Universidade Federal do Parána, Curitiba, 2013.

FERreirA, G. S. A Condição de Trabalho do Professor Temporário da Rede Municipal de Ensino de Fortaleza - CE. 70 p. Dissertação (mestrado em psicologia). Universidade de Fortaleza, Fortaleza, 2016.

FINBRA. Finanças do Brasil - Dados Contábeis dos Municípios. Disponível em http://www.tesouro.fazenda.gov.br/contas-anuais. Acesso em 21 de dez. 2019.

GEMAQUE, R. M. O. O Financiamento da Educação. O Fundef no Estado do Pará: Feitos e Fetiches. 370p. Tese (Doutorado em Educação). Universidade de São Paulo, São Paulo, 2004.

GOUVEIA, A. B.; SOUZA, A. R. Política de fundos em perspectiva histórica: mudanças de concepção da política na transição Fundef e Fundeb. Em Aberto, Brasília, v. 28, n. 93, p. 45-65, jan./jun. 2015.

GRAHAM, R. Clientelismo e Política no Brasil do Século XIX. Rio de Janeiro: Editora da UFRJ, 1997.

HILGERS, T. Clientelism and Conceptual Stretching: Differentiating among concepts and among analytical levels. Theory and Society, v. 40, n. 5, p. 567$588,2011$.

IBGE. Instituto Brasileiro de Geografia e Estatística. Disponível em https:/ / censo2010.ibge.gov.br/sinopse/index.php?uf $=15 \& d a d o s=8$ e https:// cidades. ibge.gov.br/brasil/pa/portel/panorama e https://sidra.ibge.gov.br/pesquisa/ cempre/tabelas/brasil/2017 e https://sidra.ibge.gov.br/pesquisa/pib-munic/ tabelas. Acesso em 10 de nov. de 2019. 
KUSHNIR, K. Eleições e Representação no Rio de Janeiro. Bonsucesso: Relume Dumará, 1999.

LOPEZ, F. G. A política cotidiana dos vereadores e as relações entre o executivo e o legislativo em âmbito municipal: o caso do município de Araruama. Revista de Sociologia Política, v.22, p. 153-177, jun. 2004.

MARQUES, M. J. A figura do professor com contrato temporário: um estudo de caso no Liceu do Conjunto Ceará. Dissertação (Mestrado Profissional em Avalição de Políticas Públicas). Universidade Federal do Ceará, Fortaleza, 2006.

MPPA. Ministério Público do Estado do Pará. Ação requer suspensão de contratos temporários e nomeação de concursados. Portel, 26 de ago. de 2019. Disponível em https://www2.mppa.mp.br/noticias/acao-requer-suspensao-decontratos-temporarios-e-contratacao-de-concursados.htm. Acesso em 11 de dez. 2019.

NASCIMENTO, C. B. Professores em regime de contrato temporário: uma análise do impacto no rendimento dos alunos das escolas públicas estaduais do Ceará. Dissertação (Mestrado em Economia). Universidade Federal do Ceará, Fortaleza, 2014.

NAUROSKI, E. A. Trabalho docente e subjetividade: a condição dos professores temporários (PSS) no Paraná. Tese (Doutorado em Sociologia). Universidade Federal do Paraná, Curitiba, 2014.

PALMEIRA, M.; GOLDMAN, M. (orgs.). Antropologia, Voto e Representação Política. Rio de Janeiro: Contra Capa Livraria, 1996.

PARÁ. Lei n. 8.186, de 23 de junho de 2015. Aprova o Plano Estadual de Educação - PEE e dá outras providências. Belém, PA, 24 jun. 2015.

PNUD. Programa das Nações Unidas para o Desenvolvimento. Disponível em: http://www.atlasbrasil.org.br/2013/. Acesso em 14 de nov. de 2019.

PORTEL. Lei Orgânica do Município de Portel, de 5 de abril de 1990. Portel, PA, 1990. 
PORTEL. Lei Municipal n. 634/01, de 23 de julho de 2001. Dispõe sobre o Plano de Carreira e Remuneração do Magistério Público do Município de Portel e dá outras providências. Portel, PA, 2001.

PORTEL. Lei Municipal n. 847, de 23 de junho de 2015. Aprova o Plano Municipal de Educação - PME de dá outras providências. Portel, PA, 2015.

PORTEL. Decreto $\mathbf{n}^{\circ}$ 187/GP/2017, de 06 de junho de 2017. Dispõe sobre a criação e nomeação de comissão de reestruturação do Plano de Cargos, Carreira e Remuneração dos Profissionais do município de Portel, e dá outras providências. Portel, PA, 2017.

PORTEL. Edital $n^{0}$ 001/2018, retificado pelo edital $n^{0} 002 / 2018$. Portel, Prefeitura Municipal de Portel, 2018.

QUEIROZ, M. I. P. O mandonismo local na vida política brasileira e outros ensaios. São Paulo: Alfa-Omega, 1976.

QUIBAO NETO, J..; PINTO, J.M.R. O perfil dos docentes não concursados na rede estadual de ensino de São Paulo. Fineduca - Revista de Financiamento da Educação, v. 6, n. 10, 2016.

SANTOS, J. P. S. Professores temporários da rede estadual de São Paulo: análise da política de pessoal da perspectiva orçamentária. Guarulhos. 133 p. Dissertação (Mestrado em Educação). Universidade Federal de São Paulo, Guarulhos, 2016.

SEKI, A. K. et. al. Professor temporário: um passageiro permanente na Educação Básica brasileira. Práxis Educativa, Ponta Grossa, v. 12, n. 3, p. 942-959, set./ dez. 2017.

SIOPE. Sistema de Informações sobre Orçamentos Públicos em Educação. Disponível em https://www.fnde.gov.br/siope/relatorioRREOMunicipal2006. do. Acesso em 10 de out. de 2019.

TSE. Tribunal Superior Eleitoral. Disponível em http://www.tse.jus.br/ eleitor/estatisticas-de-eleitorado/consulta-por-municipio-zona. Acesso em $13 \mathrm{de}$ nov. de 2019. 
YIN, R. K. Estudo de caso: planejamento e métodos. Porto Alegre : Bookman, 2001.

\section{Ariel Feldman}

Doutor em História Social pela Universidade de São Paulo. Professor no Programa de Pós-Graduação em Educação em Cultura do Campus Universitário do Tocantins. E-mail: aridu18@yahoo.com.br

\section{Charles Alberto de Souza Alves}

Doutor em Educação na Linha de Políticas Públicas Educacionais pela UFPA/ PPGED. Docente de Cursos Técnicos e Especialização em Agroecologia e Informática Educativa. E-mail: charlesceleste32@gmail.com

Recebido em 17/04/2020

Aprovado em 06/07/2020 